\title{
NOTES PRÉLIMINAIRES
}

\section{OBTENTION IN VITRO DES STADES HÉPATIQUES \\ DE PLASMODIUM FALCIPARUM}

\author{
D. MAZIER*, R. L. BEAUDOIN**, S. MELLOUK*, P. DRUILHE*, B. TEXIER*, \\ J. TROSPER ${ }^{* *}$, F. MILTGEN***, I. LANDAU***, C. PAUL**, O. BRANDICOURT ${ }^{*}$, \\ C. GUGUEN-GUILLOUZO****, P. LANGLOIS**** et M. GENTILINI*.
}

In vitro cultivation of the exoerythrocytic stages of Plasmodium falciparum.

SUMMARY. Sporozoïtes of Plasmodium falciparum, obtained by membrane feeding of Anopheles freeborni or A. stephensi with cultured gametocytes, were used to infect monolayers of human hepatocytes. Fluorescent labelling with an African serum as well as Giemsa staining performed from day one to day 7 of cultures, demonstrated the presence of numerous hepatic schizonts measuring up to $40 \mu \mathrm{m}$.

En utilisant une méthode similaire à celle employée précédemment pour obtenir la schizogonie hépatique complète de P. vivax (Mazier et al., 1983; Mazier et al., 1984), nous nous sommes attachés à obtenir les stades hépatiques de $P$. falciparum.

Les hépatocytes humains ont été ensemencés en monoculture à raison de $6 \times 10^{\mathrm{s}}$ cellules par boîte de Pétri de $35 \mathrm{~mm}$. Au cours de deux manipulations successives, les cultures ont été infestées en ajoutant 5 à 10 paires de glandes salivaires d'Anopheles freeborni ou A. stephensi gorgés sur cultures de gamétocytes de $P$. falciparum (souche NF 54 et clone 7 G8).

* Département de Parasitologie et de Médecine tropicale, Groupe Hospitalier Pitié-Salpêtrière, 47 Boulevard de l'Hôpital, F 75651 Paris Cedex 13.

** NMRI, Bethesda, Maryland.

*** Laboratoire de Zoologie-Vers, associé au CNRS, Muséum National d'Histoire Naturelle, 61 rue Buffon, F 75231 Paris Cedex 05.

**** Unité de Recherches Hépatologiques-U 49, INSERM, Hôpital Pontchaillou, F 35011 Rennes.

***** Service de Chirurgie, Groupe Hospitalier Pitié-Salpêtrière, Paris.

Accepté le 3 I juillet 1984 . 
Des schizontes hépatiques ont été recherchés par fluorescence et/ou coloration au Giemsa. Les tests d'immunofluorescence indirecte ont été pratiqués sur les cultures fixées au méthanol avec un sérum d'adulte africain hyperimmun dilué au $1 / 50^{\mathrm{e}}$ et un conjugué fluorescent (Nordic) dilué au $1 / 30^{\mathrm{e}}$ dans une solution de bleu Evans à $1 / 2000$.

Les fixations effectuées à 21 heures ont permis d'objectiver un grand nombre de sporozoïtes extracellulaires fixés ou non à la surface des cellules et de plus rares formations fluorescentes arrondies intracytoplasmiques mesurant 3 à 4 m $\mu$.

Des schizontes ont été observés dans toutes les cultures fixées 3, 5, 6 et 7 jours après l'infestation. De forme ronde, ou plus rarement ovale, en position intra-cytoplasmique, le plus souvent juxtanucléaire, ils fluorescent vivement et se détachent de façon nette sur le fond rouge de la préparation. Dans la majorité des cas, un renforcement périphérique de la fluorescence est observé, similaire à celui décrit précédemment sur des schizontes obtenus in vivo (Druilhe et al., 1984).

Les cultures les plus riches contiennent jusqu'à 650 formes hépatiques au $6^{\mathrm{e}}$ jour. En coloration au Giemsa, un début de pseudo-cytomérisation est visible sur les schizontes les plus âgés (35 à $40 \mathrm{~m} \mu$ ). Des expériences complémentaires sont en cours pour déterminer si les schizontes peuvent achever leur maturation complète et libérer des mérozoïtes infectieux.

Ce travail a pu être réalisé grâce à l'appui financier du ministère de la Recherche et de 1'Industrie (82.L.0760 et 82.L.0787), du NMRDC 3Mr62770A870AF 312 , de 1'INSERM, et du Programme Spécial/P.N.U.D./Banque Mondiale/OMS/de recherche et de formation concernant les maladies tropicales $(840105$ et Tr6/1 $81 / \mathrm{M} 2 / 39)$.

\section{BIBLIOGRAPHIE}

Druilhe P., Puebla R., Mrltgen F., Perrin L., Gentilini M. - Species and stage specific antigens in exo-erythrocytic stages of Plasmodium falciparum. Am. J. Trop. Med. Hyg., $1984,33,336-34 \mathrm{I}$.

Mazier D., Landau I., Miltgen F., Druilhe P., Guguen-Guillouzo C., Baccam D., Baxter J., CHigot J. P., Gentilini M. - Infestation in vitro d'hépatocytes humains par des sporozoites de Plasmodium vivax : schizogonie et libération de mérozoïtes infestants pour des hématies humaines. Ann. Parasitol. Hum. Comp., 1983, s8, 405-406.

Mazier D., Landau I., Druilhe P., Miltgen F., Guguen-Guillouzo C., Baccam D., Baxter J., Chigot J. P., Gentilini M. - Cultivation of the liver forms of Plasmodium vivax in human hepatocytes. Nature, $1984,307,367-369$. 